\title{
Candida albicans Antigen Injection
}

National Cancer Institute

\section{Source}

National Cancer Institute. Candida albicans Antigen Injection. NCI Thesaurus. Code C150379.

An injectable formulation composed of antigens derived from the culture filtrate and cells of two different strains of Candida albicans (C. albicans), with immunomodulatory activity. Upon intralesional administration into the cutaneous human papilloma virus (HPV)infected warts, the $\mathrm{C}$. albicans antigens stimulate the immune system to mount a cytotoxic T-lymphocyte ( $C T L$ )-mediated immune response against the injected antigens and cause a delayed type hypersensitivity response against other local antigens, including antigens within the wart tissue. This leads to the production of Th1 cytokines, and the activation of natural killer (NK) cell- and CT L- mediated killing of HPV-infected cells. This causes clearing of both local and distant warts, and prevents both HPV infection and wart formation that results from HPV infection. 